\title{
El procedimiento de modificación de la capacidad en España diez años después de la entrada en vigor de la Convención de la ONU sobre los derechos de las personas con discapacidad
}

\author{
O procedimento de modificação da capacidade na Espanha dez anos após a \\ entrada em vigor da Convenção da ONU sobre os direitos das pessoas com \\ deficiência
}

The capacity modification procedure in Spain ten years after the implementation of the UN Convention on the rights of persons with disabilities

Pedro Botello Hermosa*

\section{Resumen}

\begin{abstract}
Diez años después de la entrada en vigor de la Convención de la ONU sobre los Derechos de las Personas con Discapacidad en España, podemos afirmar dos ideas fundamentales respecto a la adaptación de su artículo 12 a nuestro Ordenamiento: $1^{\circ}$.- El procedimiento de incapacitación sigue estando formado por las mismas figuras antes y después de la Convención. $2^{\circ}$.- El orden de preferencia de las figuras de protección cambió radicalmente, ya que tras la entrada en vigor de la Convención la curatela, casi inexistente hasta entonces, ha pasado a ser la figura preferente y la tutela, que antes de la Convención era la figura principal del procedimiento de incapacitación, se ha convertido en una institución totalmente residual.
\end{abstract}

Palabras Claves: Discapacidad. Naciones Unidas. Procedimientos en materia de capacidad de las personas. Medidas de apoyo y asistencia. Curatela.

\section{Resumo}

Dez anos após a entrada em vigor da Convenção da ONU sobre os Direitos das Pessoas com Deficiência na Espanha, podemos afirmar duas ideias fundamentais com respeito à adaptação do seu artigo 12 ao nosso Ordenamento: $1^{\circ}$ - $O$ procedimento de incapacitação continua a estar formado pelas mesmas figuras, antes e depois da Convenção; $2^{\circ}$. $A$ ordem de preferência das figuras de proteção mudou radicalmente, já que, depois da entrada em vigor da Convenção, a curatela, quase inexistente até então, passou a ser a figura preferida, e a tutela, que antes da Convenção era a figura principal do procedimento de incapacitação, converteu-se numa instituição totalmente residual.

Palavras-chave: Deficiência. Nações Unidas. Procedimentos em matéria de capacidade das pessoas. Medidas de apoio e assistência. Curatela.

\section{Abstract}

Ten years after the implementation of the UN Convention on the Rights of Persons with Disabilities in Spain, we can claim two fundamental ideas regarding the adaptation of its article 12 in our legal framework: $1^{\circ}$.- The incapacitation procedure still consists of the same legal figures before and after the Convention. $2^{\circ}$.- The order of preference of the legal figures of protection changed radically, as after thei mplementation of the Convention, the curator ship, almost non existent until then, became the preferred legal figure and guardianship, that was the main figure of the incapacitation procedure before the Convention, became a totally residual institution.

Keyword: Disability. United Nations. Incapacitation procedures. Measures of support and assistance. Guardianship.

Doctor por la Universidad de Sevilla. Profesor del Centro San Isidoro, Adscrito a la Universidad Pablo de Olavide de Sevilla. Sevilla - Espanha. E-mail: pedrobh4@gmail.com. 


\section{Introducción}

Dado que desde su entrada en vigor, la Convención forma parte, a todos los efectos, del Ordenamiento jurídico español, en virtud de lo dispuesto en los artículos $10.2^{1}$ y $96.1^{2}$ de la Constitución Española, así como de lo recogido en el artículo $1.5^{3}$ de nuestro C.c., en el presente artículo expondré cómo afectó la entrada en vigor en mayo de 2008 de la Convención de la ONU sobre los Derechos de las Personas con Discapacidad (en adelante, la Convención), al procedimiento que existe en España para modificar la capacidad de obrar de las personas que lo necesiten, procedimiento que en la actualidad puede seguir siendo definido como "de incapacitación", aunque particularmente entiendo que lo apropiado es referirse al mismo como "procedimiento de modificación de la capacidad", ya que así lo hace ya Ley 15/2015, de Jurisdicción Voluntaria precisamente para cumplir con el espíritu de la Convención, cuando expone en el apartado III de su preámbulo que

También se busca la adaptación a la Convención de las Naciones Unidas sobre los Derechos de las Personas con Discapacidad, hecha en Nueva York el 13 de diciembre de 2006, la cual afecta a la nueva terminología, en la que se abandona el empleo de los términos de incapaz o incapacitación, y se sustituyen por la referencia a las personas cuya capacidad está modificada judicialmente.

Dicho esto, creo que lo primero que hay que aclarar al lector cuando se habla de personas con capacidad modificada judicialmente (o incapacitadas según el Código civil y la Ley de Enjuiciamiento Civil) es que al referirnos a ellas no estamos haciendo referencia a las personas con discapacidad.

\section{Personas con discapacidad y personas con su capacidad modificada judicialmente}

La discapacidad se consigue mediante una resolución administrativa, mientras que la modificación de la capacidad de una persona sólo y exclusivamente se producirá mediante una sentencia judicial firme. En esta línea expresaba Palau Benlloch (2016, p. 10) que "no existen ya procedimiento de incapacidad. Nadie es incapaz. Se trata de determinar cuáles son sus capacidades, y los apoyos que necesita para ejercer adecuadamente su capacidad jurídica. Son personas con capacidad modificada judicialmente."

Así, mientras que las persona con discapacidad son definidas en el artículo 4 de la Ley General de derechos de las personas con discapacidad y su inclusión social como "aquellas que presentan deficiencias físicas, mentales, intelectuales o sensoriales, previsiblemente permanentes que, al interactuar con diversas barreras, puedan impedir su participación plena y efectiva en la sociedad, en igualdad de condiciones con los demás," respecto a las personas con su capacidad modificada judicialmente expone el artículo 200 del C.c. que "son causas de incapacitación las enfermedades o deficiencias persistentes de carácter físico o psíquico, que impidan a la persona gobernarse por sí misma”.

Es decir, que las personas con su capacidad modificada judicialmente son aquellas que debido a una enfermedad o deficiencia persistente no pueden autogobernarse y de ahí que se le nombre un apoyo que le complemente en su capacidad tras el procedimiento de modificación de la capacidad, pudiendo recaer la falta de autogobierno tanto en la esfera personal de la persona (por ejemplo, falta de atención y de cuidado), como en su esfera patrimonial (respecto a la administración u disposición de los bienes), mientras que por su parte, la personas con discapacidad pueden autogobernarse sin ningún problema en todos los ámbitos de su vida, motivo por el cual no debemos confundir a las personas con discapacidad y a las personas con su capacidad modificada judicialmente.

El artículo 10.2 de la Constitución Española establece: "Las normas relativas a los derechos fundamentales y a las libertades que la Constitución reconoce se interpretarán de conformidad con la Declaración Universal de Derechos Humanos y los tratados y acuerdos internacionales sobre las mismas materias ratificados por España".

2 Expresa el art. 96.1 de nuestra Constitución: "Los tratados internacionales válidamente celebrados, una vez publicados oficialmente en España, formarán parte del ordenamiento interno. Sus disposiciones sólo podrán ser derogadas, modificadas o suspendidas en la forma prevista en los propios tratados o de acuerdo con las normas generales del Derecho internacional".

$3 \quad$ El C.c. expone en su artículo 1.5: "Las normas jurídicas contenidas en los tratados internacionales no serán de aplicación directa en España en tanto no hayan pasado a formar parte del ordenamiento interno mediante su publicación íntegra en el Boletín Oficial del Estado".

4 Así se siguen refiriendo a él tanto el Código civil en su artículo 199 y siguientes, como la Ley de Enjuiciamiento Civil en su artículo 756 y siguientes. 
Dicho esto, lo cierto es que en la inmensa mayoría de $\operatorname{casos}^{5}$ en los que se acaba modificando judicialmente la capacidad de una persona, ésta seguramente sufría antes algún tipo de discapacidad, y debido a la evolución de su enfermedad haya llegado a un punto por el que no pueda autogobernarse y finalmente se decida modificar su capacidad.

Pero vuelvo a insistir en que no por ello se pueden confundir las personas con discapacidad en general, con las personas con su capacidad modificada judicialmente.

\section{Alcance del artículo 12 de la Convención}

Exige la Convención en su artículo 12 a los Estados Partes que reconozcan que todas las personas con o sin discapacidad tienen las mismas capacidades, y que aquéllas que necesiten algún apoyo lo reciban, pero siempre limitándose lo menos posible su capacidad de obrar.

O dicho de otra forma, lo que se pretende desde la ONU con el contenido del artículo 12 es que dejemos de preguntarnos hasta qué grado se ha de modificar la capacidad de obrar de la persona que lo necesite, y empecemos a cuestionarnos qué nivel de apoyo o asistencia necesita esa misma persona para desarrollar su vida con total normalidad, pudiendo ejercer su capacidad de obrar en igualdad de condiciones con el resto de personas, es decir, que puedan adoptar libremente todo tipo de decisiones en cualquier ámbito de su vida, siendo apoyados en aquellos casos en que lo necesiten.

¿Y qué cambios conllevó la implementación de dicho artículo de la Convención en el entonces procedimiento de incapacitación español?

Pues lo primero que hemos de destacar es que, en cuanto a su estructura, es decir, a las figuras que lo componían en mayo de 2008 (tutela, curatela, patria potestad prorrogada y defensor judicial) el procedimiento de incapacitación español la entrada en vigor de la Convención no supuso ninguna modificación, o lo que es lo mismo, que dicho procedimiento sigue estando compuesto por las mismas figuras.

Y es que, nuestro Tribunal Supremo en su primer pronunciamiento sobre tal cuestión, dejó claro que el procedimiento de incapacitación español vigente en 2008 cumplía con todas las exigencias del artículo 12 de la Convención. Concretamente fue en la importantísima sentencia 282/2009, de 29 de abril ${ }^{6}$, cuando en su Fundamento de Derecho Séptimo al que dio por título "Los Sistemas de Protección" expuso nuestro Alto Tribunal que:

Otra cosa distinta es si el sistema de protección debe ser o no rígido, en el sentido de que no debe ser estándar, sino que se debe adaptar a las conveniencias y necesidades de protección de la persona afectada y además, constituir una situación revisable, según la evolución de la causa que ha dado lugar a tomar la medida de protección.

Esta Sala, en la ya citada sentencia de 5 marzo 1947 (RJ 1947, 343), entendió que la ley entonces vigente tenía una laguna, cuando no permitía regular los efectos de la debilidad o el atraso mental como distintos de los de la demencia o locura, laguna que colmó ajustando la extensión de la tutela al grado de intensidad con que se manifiesta en cada caso la perturbación, sentencia que fue seguida por las de 13 mayo 1960, 25 marzo 1961, 17 abril 1965 y 6 febrero 1968. La reforma del Código de acuerdo con la ley 13/1983, de 24 octubre (RCL 1983, 2298) introdujo un sistema proteccionista, pasando del concepto tradicional capacidad/incapacidad a una situación adaptable a las necesidades de protección del destinatario de la medida. Desde entonces se viene sosteniendo por la jurisprudencia y la doctrina que la incapacitación sólo es un sistema de protección frente a limitaciones existenciales del individuo y que nunca podrá discutirse la cualidad de persona del sometido a dicho sistema de protección. La ley 41/2003, de 18 noviembre (RCL 2003, 2695), de protección patrimonial de las personas con discapacidad, introduce un nuevo sistema de protección, sin incapacitación, para personas en razón de su discapacidad, con relevancia en el ámbito del Derecho civil; este sistema no depende, pues, de la incapacitación, ni constituye un estado civil y se aplica a quienes estén afectados por una minusvalía psíquica igual o mayor al 33\% y las afectadas por una minusvalía física o sensorial igual o superior al 65\% (Art. 2.2 ).

\footnotetext{
También existen excepciones de personas que no tienen ninguna discapacidad reconocida administrativamente y de pronto se le modifica su capacidad judicialmente, como puede ser el caso de personas que sufran un accidente de tráfico y queden en coma, en estado vegetativo, etc. 6 Sentencia núm. 282/2009 de 29 abril. RJ 2009\2901.
} 
La STC 174/2002, de 9 octubre (RTC 2002, 174) dice que "En el plano de la constitucionalidad que nos corresponde hemos de declarar que el derecho a la personalidad jurídica del ser humano, consagrado en el art. 6 de la Declaración universal de los derechos humanos de 10 de diciembre de 1948 (LEG 1948, 1), lleva implícito el reconocimiento del derecho a la capacidad jurídica de la persona, por lo que toda restricción o limitación de su capacidad de obrar afecta a la dignidad de la persona y a los derechos inviolables que le son inherentes, así como al libre desarrollo de la personalidad (art. 10.1 CE (RCL 1978, 2836). En consecuencia, la declaración de incapacitación de una persona sólo puede acordarse por sentencia judicial en virtud de las causas establecidas en la Ley (art. 199 CC (LEG 1889, 27), mediante un procedimiento en el que se respeten escrupulosamente los trámites o diligencias que exigía el art. 208 CC (y que en la actualidad se imponen en el vigente art. 759 LECiv (RCL 2000, 34, 962) que, en la medida en que van dirigidas a asegurar el pleno conocimiento por el órgano judicial de la existencia y gravedad de las enfermedades o deficiencias persistentes de carácter físico o psíquico que concurren en el presunto incapaz y que le inhabilitan para gobernarse por sí mismo, que son la causa y fundamento de su incapacitación (arts. 199 y 200 CC ), se erigen en garantías esenciales del proceso de incapacitación [...]. La incapacitación total sólo deberá adoptarse cuando sea necesario para asegurar la adecuada protección de la persona del enfermo mental permanente, pero deberá determinar la extensión y límites de la medida y deberá ser siempre revisable.

De este modo, sólo esta interpretación hace adecuada la regulación actual con la Convención, por lo que el sistema de protección establecido en el Código civil sigue vigente, aunque con la lectura que se propone:

$1^{\circ}$ Que se tenga siempre en cuenta que el incapaz sigue siendo titular de sus derechos fundamentales y que la incapacitación es sólo una forma de protección. Esta es la única posible interpretación del artículo 200 CC y del artículo 760.1 LEC.

$2^{\circ} \mathrm{La}$ incapacitación no es una medida discriminatoria porque la situación merecedora de la protección tiene características específicas y propias. Estamos hablando de una persona cuyas facultades intelectivas y volitivas no le permiten ejercer sus derechos como persona porque le impiden autogobernarse. Por tanto no se trata de un sistema de protección de la familia, sino única y exclusivamente de la persona afectada.

Es decir, que nuestro Tribunal Supremo en esta sentencia declaró que el procedimiento de incapacitación español (o modificación judicial de la capacidad) es acorde al contenido y al espíritu de la Convención en cuanto al máximo respeto y reconocimiento de la capacidad de las personas, y por ello no considera necesario ni oportuno que el mismo sufre una modificación en cuanto a su estructura.

Por mi parte coincido con tal idea, ya que como dice el Supremo, a través de este procedimiento lo único que se hace es proteger a personas cuyas facultades intelectivas y volitivas le impiden autogobernarse y no le permiten ejercer sus derechos como persona, o lo que es lo mismo, el procedimiento de modificación judicial de la capacidad es el cauce legal para proteger a aquellas personas que en mayor o menor medida carezcan de autogobierno, y tiene por finalidad completar la capacidad de la persona en el ámbito que lo necesite, y como procedimiento de protección que es, ofrece una serie de garantíasde gran importancia a favor de la persona que lo necesite, garantías que aparecen comprendidas entre los artículos 756 y siguientes de la Ley de Enjuiciamiento Civil y de entre las que destacan las pruebas que se van practicando durante el íter procesal de incapacitación, como es la audiencia de los parientes más próximos frente al juez, o el reconocimiento personal por parte del propio juez respecto a la persona que puede estar necesitada de protección, así como la elaboración de dictámenes periciales que se realizan para ver el verdadero alcance de la enfermedad o deficiencia en cuestión.

Otra garantía muy importante a favor de la persona cuya protección se interesa es que durante todo el procedimiento el Ministerio Fiscal interviene velando siempre por su protección, aunque sin duda la garantía más importante de todas es que la modificación de la capacidad de una persona sólo se puede determinar mediante sentencia judicial firme, sentencia que deberá fijar qué institución o figura de guarda se fija para proteger a la persona que lo necesita y el alcance de dicha institución, siendo precisamente en este punto concreto, en el de elegir la figura de protección y su alcance, en el que la Convención de la ONU supuso un cambio radical en el sistema civil de incapacitación español, ya que a partir de entonces los jueces españoles optan en la inmensa mayoría de los casos por la curatela como medio de protección 
idóneo a favor de la persona necesitada de protección, quedando relegada la tutela a un plano totalmente residual, justo al contrario de lo que pasaba en España antes de la entrada en vigor de la Convención.

\section{El auge de la curatela frente a la tutela como institución de guarda preferida por los tribunales españoles tras la Convención de la ONU}

En la actualidad en España, tras la entrada en vigor de la Convención, no hay ninguna duda respecto a que la figura principal del procedimiento de modificación de la capacidad español es la curatela.

Pero no siempre fue así, de hecho, podemos afirmar que hasta entonces la curatela era una institución casi inexistente en nuestro Ordenamiento jurídico, ya que tenía un carácter totalmente residual frente a la tutela, que desde la promulgación del Código civil español había venido siendo la figura principal del procedimiento de incapacitación tal y como afirma de forma unánime nuestra doctrina o el propio Tribunal Supremo en las sentencias que dedica al respecto tras la entreda en vigor de la Convención.

Afirma Vivas Tesón (2012, p. 25-26) al intentar razonar por qué no se ha usado en nuestro sistema la figura de la curatela que

[...] si bien la Ley 13/1.983, de 24 de octubre, que adaptaba nuestro viejo Código civil a los principios constitucionales, introdujo un sistema en el cual la incapacitación judicial debía adecuarse a las concretas exigencias de la persona enferma (la sentencia de incapacitación debe fijar la extensión y límites), permitiéndole, en su caso, realizar actos personalísimos (p. ej. matrimonio, reconocimiento de un hijo natural, otorgar testamento o el derecho al sufragio activo), en su aplicación práctica, ha persistido (o, al menos, ésa es mi impresión, tal vez equivocada) una predominante visión económica y patrimonial de la institución jurídica, dejando poco espacio a la consideración de la personalidad y libertad del individuo.

¿Pero qué supone que la institución de guarda elegida para proteger a una persona sea la tutela o la curatela? Como bien cuenta Páramo de Santiago (2017, p. 124),

[...] la forma de apoyo más intensa es la tutela, que puede resultar necesaria cuando la persona con discapacidad no pueda tomar decisiones en los asuntos de su incumbencia, ni por sí misma ni tampoco con el apoyo de otras personas. [...] Sin embargo, es posible la curatela, como medida de protección de menor intensidad, en la medida en la que pueda ser suficiente un apoyo menos intenso, solo como ayuda para tomar las decisiones que le afecten, pero sin sustituir a la persona con discapacidad. En el sistema legal que establece el Código Civil (arts. 287, 288 y 289), se concibe como un sistema mediante el cual se otorga asistencia, como un complemento de capacidad, sin sustituir a la persona con discapacidad.

En definitiva, mientras que la tutela supone la sustitución en la toma de decisiones de la persona tutelada por parte de su tutor, la curatela conlleva la asistencia o el apoyo en la toma de decisiones de la persona curatelada por parte del curador. Es decir, que mientras que el tutor tomará las decisiones oportunas en nombre del tutelado, el curador únicamente podrá asistir y apoyar al curatelado en su toma de decisiones, tal y como refleja el artículo 289 del Código civil cuando expone que "La curatela de los incapacitados tendrá por objeto la asistencia del curador para aquellos actos que expresamente imponga la sentencia que la haya establecido". Coincido con los autores Fábrega Ruíz y González Ruíz (2016, p. 2) cuando afirman que:

[...] no podemos olvidar que la modificación de la capacidad supone una limitación para el ejercicio de determinados derechos de forma aislada, ya que los realiza por nosotros el padre o tutor o debemos realizarlos con el curador, y por ello debe realizarse sólo si es estrictamente necesario y en lo que, efectivamente, lo sea. El art. 760.1 de la Ley de Enjuiciamiento Civil exige que la sentencia gradúe de forma correcta el alcance de la modificación de la capacidad. Debemos preguntarnos qué es lo que el discapaz debe hacer, según su entorno familiar y social, según su patrimonio, etc., y ponerlo en relación con lo que no puede hacer. La modificación de la capacidad debe rellenar la diferencia. Es decir, completar lo que la persona con capacidad modificada judicialmente no puede realizar para que su capacidad de obrar en el mundo del derecho sea completa, igual a la del resto de ciudadanos. 
¿Y cómo se consigue tal complemento de la capacidad por parte de la persona que lo necesita? Pues a través del nombramiento a su favor de un curador que le asista o apoye en la toma de ciertas decisiones de su vida.

En este sentido, gran parte de nuestra doctrina más autorizada, como expone García Cantero (2014, p. 68), considera que la sentencia de mayor valor jurídico dictada por nuestro Tribunal Supremo sobre la adaptación del artículo 12 de la Convención a nuestro ordenamiento hasta la fecha es la sentencia 282/2009, de 29 de Abril de 2009. Particularmente coincido con dicha corriente doctrinal en considerar la sentencia de 2009 como el ejemplo más importante de la compatibilidad existente entre nuestro actual procedimiento de incapacitación y el espíritu de la Convención en general, ya que, me permito reiterar, el procedimiento de incapacitación español conlleva una serie de medidas de protección a favor de las personas con discapacidad que lo hacen compatible con lo exigido en la Convención.

Sin embargo, considero que en cuanto a la efectiva adaptación del artículo 12 de la Convención a nuestro Ordenamiento igual de importante que la sentencia 282/2009, de 29 de Abril lo es también la sentencia 421/2013, de 24 de junio de 2013.

Y es que, en mi opinión, no considero posible poner como ejemplo de adaptación del artículo 12 de la Convención a nuestro ordenamiento a través del procedimiento de incapacitación a la sentencia 282/2009, de 29 de Abril, ya que en la misma se siguió declarando incapaz en modo absoluto y permanente para regir su persona y sus bienes a la persona con discapacidad enjuiciada, yendo tal decisión contra el espíritu de la Convención en cuanto al ejercicio de la capacidad de obrar de las personas con discapacidad.

Particularmente entiendo que en base a la Convención, el medio de protección que dicha persona necesitaba era el nombramiento de un curador que le asistiese o apoyase en determinados actos concretos, y no su incapacitación absoluta. Tal conclusión la alcanzo en base a las afirmaciones que se hacen en la sentencia, como por ejemplo:

a) - El Juez de Primera Instancia para incapacitar a la señora expuso:

Sólo cabe limitarla en los supuestos como el que nos ocupa porque Doña V., por sí sola, le es imposible participar libremente en los distintos aspectos de la vida, personales (vestir, pasear, etc.), familiares (llevar la casa, comprar, etc.), o sociales (visitas relaciones etc.) - no puede estar presente en estas actuaciones- $\mathrm{e}$ incluso aquellas otras que vienen impuestas por la administración del patrimonio que posee (ha conferido poder general), por lo que necesita protección, vigilancia o representación de otras personas, que sustituyan o complementen aquella cualidad o estado de la que carece [...].

Pero, ¿cuál de los supuestos arriba mencionados conlleva la necesidad de privar a una persona totalmente de su capacidad de obrar? ¿Tal vez haber otorgado un poder? ¿No poder comprar, llevar la casa o recibir visitas?

Tomar cualquiera de estas razones como motivo para nombrar un tutor que rija de modo absoluto la persona y sus bienes, considero que puede entenderse contrario el espíritu de la Convención.

b) - El mismo juez tras su inspección personal a la señora, recogió:

Se trata de una persona de avanzada edad, afectada por una enfermedad visible de Parkinson, que se orienta bien en el tiempo y en el espacio, conoce sus circunstancias personales, a su familia y a su entorno, pudiendo afirmar que puede realizar actos propios de la vida cotidiana, no así complejos como sería la administración de sus bienes.

¿Acaso no parece claro que lo que necesitaba la persona en cuestión era un curador que le apoyase únicamente en su ámbito patrimonial?

c) - A todo esto hay que sumarle el contenido del informe del médico forense que actuó en primera instancia, el cual reflejó que: "aunque los diagnósticos de las enfermedades que padece no son incapacitantes por sí mismos... ante la complejidad de sus bienes, y ante la situación socio-familiar, podría llevarle a sufrir engaños por terceras personas [...]". 
Es decir, que el médico forense entendía que los diagnósticos de las enfermedades que padecía la señora no eran incapacitantes por sí mismos, pero que sí podía sufrir ésta engaños por terceras personas.

Entonces, ¿por qué no se le designó un curador para todos los actos patrimoniales, en vez de un tutor para todo su ámbito personal y patrimonial?

En base a todo lo anterior, entiendo que la Sentencia 282/2009, de 29 de abril de 2009, no es la sentencia que mejor refleja la idoneidad de la adaptación del artículo 12 de la Convención a nuestro ordenamiento jurídico.

En cambio, la Sentencia 421/2013, de 24 de junio de 2013, fue la primera en considerar el nombramiento de un curador a favor de la persona con discapacidad como medio idóneo de adaptación del artículo 12 de la Convención, a lo que hay que sumarle el interés casacional de la misma, con las consecuencias jurídicas que ello conlleva para el resto de los Tribunales españoles.

En este supuesto, la Sentencia de primera instancia declaró incapacitado al demandado, tanto para regir su persona y bienes, incluida la privación del derecho activo, como su patrimonio, y nombró tutor a una entidad pública.

El demandado interpuso recurso de apelación que fue desestimado, como también fue desestimada la solicitud del Ministerio Fiscal de que fuera sometido a curatela, interesado en la vista celebrada en la alzada, "porque las limitaciones que padece el demandado exigen acudir a la curatela".

La Sentencia fue recurrida en casación tanto el demandado como el propio Ministerio Fiscal, citando como infringida la Convención sobre los Derechos de las Personas con Discapacidad, firmada en Nueva York el 13 de diciembre de 2006, ratificada por España el 23 de noviembre de 2007, y los artículos 199, 200 y 287 del Código Civil, puestos en relación con los artículos 10, 14 , 23 y 96 de la Constitución Española. Considera que existe una clara desproporcionalidad en la medida adoptada en la Sentencia, lo que también comparte el Ministerio Fiscal, una vez practicada la prueba en segunda instancia, por lo que solicitó la instauración de una curatela, ya que en los informes periciales no hablan de limitación total, único caso en el que procedería la incapacitación total, que es la que, finalmente, se ha adoptado en contra de la proporcionalidad y adaptación a las circunstancias de la persona exigidas ambas por el artículo 12 del Convenio, privándole, incluso, de derechos fundamentales, como el de sufragio, cuando no existe ninguna referencia a la supuesta pérdida de las habilidades para que se vea privado del derecho de voto, o incluso, de la posibilidad de gobernarse por sí mismo, cuando siempre lo ha hecho para atender sus propios asuntos.

El Tribunal Supremo casó la sentencia, con las consecuencias jurídicas que ello conlleva para el futuro de este tipo de procedimientos.

El Fallo de la Sentencia es en mi opinión, el claro ejemplo de que por un lado las medidas tuitivas existentes en nuestro actual procedimiento de incapacitación son suficientes para llevar a cabo la adaptación del artículo 12 de la Convención a nuestro ordenamiento interno, y por otro lado, refleja que apostando por la curatela como medio de apoyo de las personas con discapacidad tanto en su ámbito personal como en el patrimonial, tal y como pretendía la Ley 13/198, de 24 de octubre de reforma de la tutela, no hace falta incluir ninguna medida de apoyo nueva a favor de este sector de la sociedad española. Literalmente expone el Fallo en su punto $2^{\circ}$ :

Declarar que Don Camilo es parcialmente incapaz tanto en el aspecto personal como patrimonial, la cual será complementada por un curador. En la esfera personal requerirá la intervención del curador en cuanto al manejo de los medicamentos prescritos, ayuda de su enfermedad y autocuidado, el cual decidirá en su caso la permanencia en residencia o su internamiento en un establecimiento de salud mental o de educación o formación especial. En lo que se refiere al patrimonio y economía, conservará su iniciativa pero precisará del curador para su administración, gestión y disposición, ya sea inter vivos o mortis causa, completando su incapacidad. Controlará y fiscalizará todos sus gastos, incluidos los corrientes, evitando el gasto excesivo y la manipulación por parte de terceras personas, sin perjuicio de que se le asigne una suma periódica para su consumo y necesidades cotidianas de la vida (dinero de bolsillo). 
Aunque la enorme importancia práctica de la Sentencia 421/2013 no sólo se refleja en la elección de la curatela como medio de protección ideal tanto en el ámbito patrimonial como personal, de la persona con discapacidad psíquica, sino que también destaca por su posicionamiento relativo al sufragio pasivo de la persona a incapacitar, ya que establece al respecto que en ningún caso queda afectado el derecho de sufragio del que se le privó sin justificación alguna en las otras instancias.

El artículo 29 de la Convención garantiza a las personas con discapacidad los derechos políticos y la posibilidad de gozar de ellos en igualdad de condiciones y como corolario lógico ejercer el derecho de voto que se considera conveniente y beneficioso, mientras que el artículo 3.1 b y 2 de la Ley $5 / 85$, de 19 de julio, del Régimen Electoral General, señala que los declarados incapaces en virtud de sentencia judicial firme quedarán privados del derecho de sufragio, siempre que la misma declare expresamente la incapacidad para su ejercicio, debiendo los Jueces o Tribunales que entiendan de los procedimientos de incapacitación o internamiento pronunciarse expresamente sobre la incapacidad para el ejercicio del sufragio. La pérdida del derecho de sufragio no es una consecuencia automática o necesaria de la incapacidad, sino que son compatibles la incapacitación y la reserva al incapaz de este derecho, ya que una cosa es que la persona no pueda regirse por sí misma, ni administrar su patrimonio, y otra distinta es que esa persona esté impedida para ejercitar correctamente su derecho al voto.

Es el Juez que conoce del proceso a quien corresponde analizar y valorar la situación de la persona sometida a su consideración y pronunciarse sobre la conveniencia de negar el ejercicio de este derecho fundamental. En la sentencia nada se argumenta en cuanto a que no pueda hacerlo, o que no pueda discernir el sentido de su voto, o que lo ponga en riesgo mediante la actuación de terceros, antes al contrario, su habilidad para tomar una decisión de esta clase no ha sido cuestionada y parece además conveniente que así lo haga de forma libre, como medida terapéutica para el tratamiento de su enfermedad, que puede verse afectada por el rechazo que deriva de su estado.

A modo de conclusión entiendo fundamental dejar expuesto que el mayor reflejo de la enorme importancia de la sentencia comentada, se aprecia en su interés casacional y las consecuencias jurídicas que ello conlleva para el resto de nuestros Tribunales, ya que debido al Fallo de la misma éstos quedan obligados a establecer siempre la curatela en vez de la tutela como medio de protección o asistencia a favor de la persona que lo necesite.

De hecho, desde la publicación de la Sentencia 421/2013, de 24 de junio de 2013, se han dictado más de mil sentencias de Audiencias Provinciales ${ }^{7}$, en términos idénticos, en el sentido establecer un curador como medio de protección idóneo a favor de la persona con discapacidad, en vez de un tutor tal y como se venía adoptando hasta entonces casi por defecto.

Pero no sólo en sentencias de Audiencias Provinciales, sino que el propio Tribunal Supremo sigue pronunciándose en la misma línea que ya lo hiciese en su sentencia 421/2013, de 24 de junio de 2013, como por ejemplo hizo en la sentencia $373 / 2016$, de 3 de junio ${ }^{8}$, donde fijó que

Este interés viene referido a una mujer, nacida el día $27-11-1933$, que padece una pseudodemencia
depresiva en relación con trastorno adaptativo con un deterioro cognitivo leve que, dentro de las
habilidades de la vida independiente, puede realizar tareas de autocuidado y actividades instrumentales
diarias y para la salud, con la adecuada supervisión que garantice tanto la toma de medicación
como la asistencia a las consultas psiquiátricas programadas; apoyos que también necesita para la
realización de actuaciones económicas, jurídicas y administrativas, teniendo en cuenta que desconoce
el dinero que tiene en sus cuentas y que es fácilmente influenciable por lo que podría ser engañada
en la toma de decisiones de tipo económico de cantidades importantes. Como tal debe ser protegida
en razón a esa incidencia efectiva que dichas limitaciones tienen en su autogobierno, de una forma

Entre otras, las Sentencias de AP de Pontevedra, núm. 362/2014, de 6 noviembre; SAP de Barcelona, núm. 770/2014, de 19 de noviembre; SAP de A Coruña, núm. 406/2014, de 25 noviembre; SAP de Barcelona, núm. 794/2014, de 2 diciembre; SAP de Asturias, núm. 321/2014, de 9 diciembre; SAP de León, núm. 272/2014, de 15 de diciembre; SAP de Barcelona, núm. 851/2014, de 17 diciembre; SAP de Barcelona, núm. 860/2014, de 18 diciembre; SAP de Barcelona, núm. 863/2014, de 18 diciembre; SAP de Tarragona, núm. 2/2015, de 2 de enero; SAP de Asturias, núm. 20/2015, de 22 enero; SAP de Huesca, núm. 8/2015, de 29 enero.

$8 \mathrm{RJ} / 2016 / 2311$. 
irreversible, en tanto no le permiten ejercer con absoluta normalidad sus derechos como persona; situación que no pasa en este caso por la absoluta incapacitación, incluido el ejercicio del derecho de sufragio, sino por la instauración de la curatela reinterpretada a la luz de Convención desde un modelo de apoyo y de asistencia y el principio del superior interés de la persona con discapacidad que, manteniendo la personalidad, requiere un complemento de su capacidad por un tercero en la toma de decisiones, precisamente para proteger su personalidad, en palabras de la propia Convención, en aquellos aspectos en los que puede ser necesario, no en todos, y que no son otros que los que la prueba ha puesto en evidencia. Ninguna otra conclusión se obtiene de los hechos que la sentencia considera acreditados.

\section{Conclusión}

En España desde la importantísima Sentencia 282/2009, de 29 de abril, del Tribunal Supremo queda claro que el procedimiento de incapacitación (hoy ya podemos hacer referencia a él como procedimiento de modificación de la capacidad) cumpla con el espíritu y la finalidad de la Convención respecto a la capacidad de obrar de las personas, ya que según su nuestro Alto Tribunal, las instituciones de guarda existente en nuestro procedimiento (tutela, curatela, patria potestad prorrogada y defensor judicial) son suficientes para adaptar el artículo 12 de la Convención a nuestro sistema.

Pero aunque tales herramientas fuesen suficientes para adaptar el artículo 12 de la Convención a nuestro ordenamiento, cabe cuestionarse: ¿estaban éstas siendo usadas adecuadamente?

La respuesta es clara: NO.

Y es que, en España, hasta la entrada en vigor de la Convención los procedimientos de incapacitación terminaban siempre por regla general de la misma forma: con una sentencia que consideraba que la persona en cuestión no necesitaba ser incapacitada, o, en su defecto, con una sentencia que incapacitaba totalmente a la persona en todos los ámbitos de su vida, tanto patrimonial como personal. O dicho de otra forma, la curatela tenía un carácter totalmente residual frente a la tutela.

Sin embargo, a partir de la Convención la situación cambia drásticamente a la hora de elegir los jueces españoles la institución de guarda necesaria para proteger a la persona que necesite la modificación de su capacidad, pasando a convertirse en la actualidad como el eje del procedimiento de incapacitación la curatela, y ostentando desde entonces un carácter totalmente residual la tutela como medio de protección idóneo a favor de las personas necesitadas de protección.

\section{Referencias}

FÁBREGA RUÍZ, Cristóbal Francisco; GONZÁLEZ RUÍZ. Procedimiento de modificación judicial de la capacidad de obrar de las personas. Práctica de tribunales - Revista de derecho procesal civil y mercantil, La Ley, Madrid, n. 13, 8667, p. 2, 2016.

GARCÍA CANTERO, Gabriel. ¿Persons with disability vs Personas incapacitadas... O viceversa? Revista de Derecho Civil, Madrid, v. 1, n. 4, p. 67-106, 2014.

PALAU BENLLOCH, Inmaculada. La intervención del Ministerio Fiscal en los procedimentos de internamiento urgente y determinación de la capacidad. Cuestiones de interés. Práctica de tribunales Revista de derecho procesal civil y mercantil, La Ley, Madrid, n. 123, p. 3-10, 2016.

PÁRAMO DE SANTIAGO, Casto. Modificación de la capacidad de obrar por deterioro cognitivo. Tutela o curatela: criterios para su determinación. La persona idónea para el cargo. CEFLegal - Revista práctica de derecho. Comentarios y casos prácticos, Madrid, n. 198, p. 120-127, julio 2017.

VIVAS TESÓN, Inmaculada. Más allá de la capacidad de entender y querer. Badajoz: Futuex, 2012.

Recebido em: 02/03/2018

Aprovado em: 16/06/2018 